\title{
Intra-patient comparison of parietal pleural biopsies by rigid forceps, flexible forceps and cryoprobe obtained during medical thoracoscopy: a prospective series of 80 cases with pleural effusion
}

\author{
H. Wurps ${ }^{1 *}$, N. Schönfeld ${ }^{1}$, T. T. Bauer ${ }^{1}$, M. Bock ${ }^{1}$, C. Duve ${ }^{1}$, R. Sauer ${ }^{2}$, T. Mairinger $^{2}$ and S. Griff ${ }^{2}$
}

\begin{abstract}
Background: There is only few data available on the use of cryotechnique during medical thoracoscopy. Methods: Medical thoracoscopy was performed in consecutive patients with pleural effusion. Prospectively, biopsies were taken by rigid forceps, flexible forceps and cryoprobe. Specimen size, depth and diagnostic yield were compared.

Results: 80 Patients were included. 408 biopsies were taken (205 rigid biopsies, 104 flexible biopsies, 99 cryobiopsies). Mean surface area of rigid biopsies was $22.6 \pm 20.4 \mathrm{~mm}^{2}$ (flexible biopsies: $7.1 \pm 9.3 \mathrm{~mm}^{2}$, cryobiopsies: $14.4 \pm 12.8 \mathrm{~mm}^{2}$ ). Rigid biopsies were significantly larger than cryobiopsies $(p<0.001)$ and flexible biopsies $(p<0.001)$, crybiopsies were significantly larger than flexible biopsies $(p<0.01)$. A deep biopsy containing fatty tissue was harvested in $63 \%$ of rigid biopsies (cryobiopsy: $49.5 \%$ flexible biopsy: $39.5 \%$ ). In $79 / 80$ cases $(98.7 \% 95 \% \mathrm{Cl}$ cannot be calculated) a diagnosis was obtained by rigid biopsy (cryobiopsy: 73/80 cases (91.3\% $95 \%$ Cl 86.0 - 96.5\%), flexible biopsy: 74/80 cases (92.5\% 95\% Cl 88.6 - $97.4 \%)$ ). Diagnostic yield achieved with cryobiopsies was inferior to the yield of rigid biopsies (Difference: $12.7 \%$ ), but non-inferior to flexible biopsies (Difference: $6.5 \%$ ).
\end{abstract}

Conclusion: Cryobiopsies in medical thoracoscopy are safe with high diagnostic yield, non-inferior to flexible biopsies with increased tissue quantity and quality. Cryotechnique can develop an important role in medical thoracoscopy in the near future when rigid thoracoscopy is not available.

Keywords: Medical thoracoscopy, Cryobiopsy, Parietal pleura, Rigid forceps biopsy, Flexible forceps biopsy

\section{Background}

Medical thoracoscopy in rigid and in semi-rigid technique is an efficient and safe procedure in patients with exudative pleural effusion of unknown origin. Biopsy specimen taken during semi-rigid-thoracoscopy are smaller than biopsies taken by rigid forceps but the diagnostic accuracy is said to be similar [1-11]. An advantage of semi-rigid thoracoscopy is flexibility of the

\footnotetext{
* Correspondence: henrik.wurps@helios-kliniken.de

'Department of Respiratory Medicine, Lungenklinik Heckeshorn, HELIOS Klinikum Emil von Behring, Berlin, Germany

Full list of author information is available at the end of the article
}

endoscope; yet the flexible forceps is smaller and less stable compared to the rigid forceps. Therefore, it is still under debate whether flexible pleural forceps biopsies have the same diagnostic potential as biopsies harvested with rigid forceps.

Cryotechnique was introduced as early as 1968, at first for the therapeutic management of airway diseases [12]. Since then and especially in the last ten years the use of cryotechnique has been established as a routine procedure in bronchoscopy for diagnostic and interventional therapeutic use [13-20]. No increase of complications has been described [21-24]. Furthermore, in diagnostic series it could be demonstrated that central and pulmonary tissue 


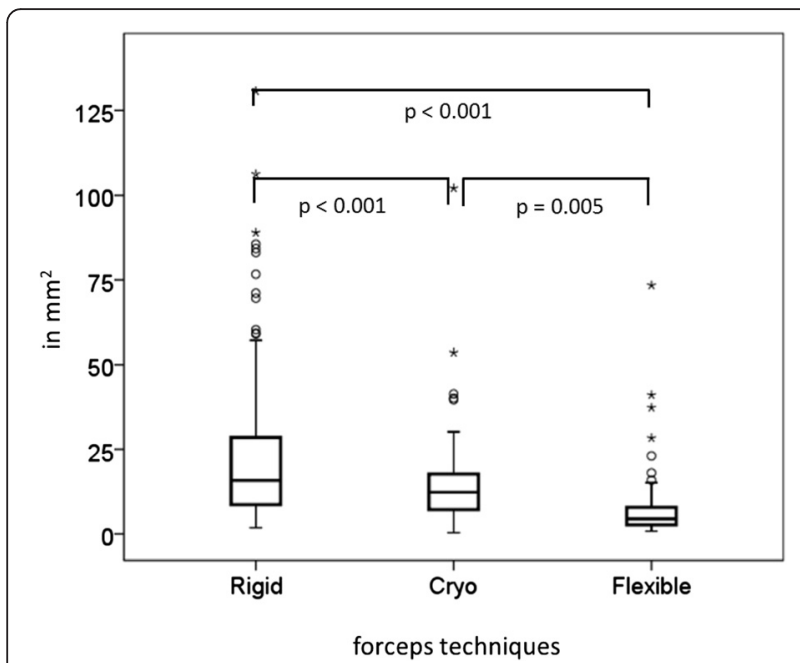

Fig. 1 Total area of specimens taken by rigid forceps, flexible forceps and cryobiopsy (in $\mathrm{mm}^{2}, \mathrm{p}$-values represent results of ANOVA with Bonferroni correction). Boxplots are shown, outliers (values that are between 1.5 and 3 times the interquartile range) are represented by circles beyond the whiskers. Extreme values (values that are more than 3 times the interquartile range) are represented by asterisk beyond the whiskers

samples were larger and better preserved compared to forceps biopsies $[25,26]$.

The use of cryotechnique in thoracoscopy has been initially described in 1989 [27], and an analgetic advantage was noted 30 years later [28]. Recently, an article describing the feasibility of cryotechnique in medical, semi-rigid thoracoscopy in fifteen patients with exsudative pleural effusion was published [29]. In this series, cryotechnique was shown to be efficient and safe without major complications.

The aim of this prospective study was to compare thoracoscopically obtained parietal pleural biopsies by rigid forceps and flexible forceps to cryobiopsies and to document the non-inferiority of cryotechnique in this procedure.

\section{Methods}

\section{Patients}

This prospective study was performed at a tertiary respiratory care center (Lungenklinik Heckeshorn) between 2012 and 2014. All consecutive patients with exsudative pleural effusion of unknown etiology with indication for medical thoracoscopy were eligible for this study. Prior to the thoracoscopy and study enrollment, all patients were informed and written consent was obtained. The study was approved by the medical ethics committee of the Charité - Universitätsmedizin Berlin (Ethikkommission, Ethikausschuss 4 am Campus Charité - Mitte).

\section{Thoracoscopy and forceps techniques}

Medical thoracoscopy with rigid single-port-of-entry technique was performed in the endoscopy suite under local anesthesia and sedation as described elsewhere [30]. All procedures were performed using a rigid thoracoscope (11 mm, Storz, Tuttlingen, Germany). To define the point of entry into the pleural cavity, an ultrasound was carried out followed by the introduction of a pneumothorax under fluoroscopic guidance. Under direct vision with the thoracoscope, all pleural fluid was removed and the pleural cavity was inspected. Afterwards, specimen were taken with rigid forceps $(3 \mathrm{~mm}$, Storz, Tuttlingen, Germany), flexible forceps $(2.8 \mathrm{~mm}$, Boston Scientific Radial Jaw, Natick, MA, USA) and cryoprobe $(2.4 \mathrm{~mm}$, Erbokryo CA, Erbe, Tübingen, Germany) in random order. Cryotechnique takes advantage of the Joule-Thompson-Effect (rapid gas release with high flow induces low temperature up to $-77^{\circ} \mathrm{Cel}-$ sius); this leads to freezing and adhesion of specimen and parietal pleura. At last, the attached tissue was extracted together with the cryoprobe. In cases of obvious malignancy a pleurodesis with talcum poudrage was performed. After the procedure, a chest tube was placed into the pleural cavity.

\section{Morphometrical and morphologic analysis of thoracoscopic biopsies}

All biopsies were processed conventionally by serial sectioning of at least 12 Hematoxylin-eosin (HE) stained section steps as it refers to be the standard procedure analyzing pleural biopsies in histological routine as described elsewhere $[25,26]$. Serial sectioning is therefore used to avoid incomplete sectioning of particles in order to provide a valid histopathological diagnosis. All biopsies were subsequently surveyed regarding size and quality. The pathologist was not blinded regarding to the technique used to obtain the biopsy.

The HE stained slides were therefore scanned by a ZEISS-MIRAX Midi Slide scanning system using the Mirax Viewer Image Software Version 1.12 (Zeiss Microimaging, Oberkochen, Germany and 3D Tech, Budapest, Hungary). Regarding biopsy size the total area was measured by interactive circling of the largest biopsy section of each serial. All areas were calculated automatically and provided in $\mathrm{mm}^{2}$. Biopsy quality was determined by tissue depth. A thoracoscopic biopsy specimen including fatty tissue of the thoracic wall was considered to be a deep biopsy and therefore of high quality.

\section{Statistical analyses}

For data analyses a statistical software (Statistical Package for Social Sciences, Version 22.0; SPSS, Chicago, IL, USA) was used on a Windows XP operating system (Microsoft; Redmond, WA, USA). Results were expressed as 
Table 1 Comparison of forceps techniques concerning number of biopsies and inclusion of fatty tissue

\begin{tabular}{llllc}
\hline & $\begin{array}{l}\text { Number } \\
\text { of biopsies }\end{array}$ & $\begin{array}{l}\text { Positive for } \\
\text { fat tissue }\end{array}$ & $\begin{array}{l}\text { Negative for } \\
\text { fatty tissue }\end{array}$ & $\begin{array}{l}\text { Biopsies incl. } \\
\text { fatty tissue (\%) }\end{array}$ \\
\hline $\begin{array}{l}\text { Rigid forceps } \\
\text { biopsy }\end{array}$ & 205 & 129 & 76 & 62.9 \\
$\begin{array}{l}\text { Flexible } \\
\text { forceps } \\
\text { biopsy }\end{array}$ & 104 & 41 & 63 & 39.4 \\
\begin{tabular}{l}
$\begin{array}{l}\text { Cryoprobe } \\
\text { biopsy }\end{array}$ \\
\hline
\end{tabular} & 99 & 49 & 50 & 49.5 \\
\hline
\end{tabular}

frequencies or as mean $\pm \mathrm{SD}$. The multiple comparison of surface area of the three methods (rigid, flexible, and cryobiopsy) were performed by ANOVA with post-hoc Bonferroni correction.

The following method was used to weigh observed differences between diagnostic success rates to establish a histopathological diagnosis. Two-sided $95 \%$ confidence intervals $(\mathrm{CI})$ for single proportions were calculated according to a standard formula $\left(\mathrm{CI}=\mathrm{p} \pm \mathrm{Z}_{\alpha / 2} \times \sqrt{ }[(\mathrm{p} \times \mathrm{q}) /\right.$ $\mathrm{n}]$ ) for all proportions (cases diagnosed (x) over all cases (n)) when $x-n \geq 5$. We used this statistical method to assume non-inferiority for the differences in success rates. Non-inferiority was assumed if the difference of the lower limit of this confidence interval of the inferior method was not larger than $10 \%$ compared to the highest observed success rate (assumed this to be higher than $90 \%$ ).

The significance level of the analyses was set to $5 \%$, and exact $p$ values were reported were appropriate.

\section{Results}

Eighty patients with a mean age of $67.5 \pm 13.5$ years were included in the study. For each patient, three to four biopsies by rigid forceps were taken. Due to the duration of the procedure, one to two cryobiopsies were taken as well as one to two biopsies by flexible forceps. Altogether, 408 biopsies were taken and analyzed (205

Table 2 Overview of histopathological diagnosis and the number of cases

\begin{tabular}{ll}
\hline Histopathological diagnosis & Number of cases (\%) \\
\hline Idiopathical chronic pleuritis & $33 / 80(41 \%)$ \\
Non-small cell lung cancer & $19 / 80(24 \%)$ \\
Pleural carcinomatosis by breast cancer & $11 / 80(14 \%)$ \\
Lymphoma & $4 / 80(5 \%)$ \\
Pleural carcinomatosis by other solid malignoma & $4 / 80(5 \%)$ \\
Malignant mesothelioma & $3 / 80(4 \%)$ \\
Tuberculous pleurisy & $3 / 80(4 \%)$ \\
Small cell lung cancer & $2 / 80(3 \%)$ \\
Asbestosis & $1 / 80(1 \%)$ \\
Total & $80 / 80(100 \%)$ \\
\hline
\end{tabular}

biopsies by rigid forceps, 104 biopsies by flexible forceps, and 99 biopsies by cryoprobe).

The mean surface area of biopsies taken with the rigid forceps was $22.6 \pm 20.4 \mathrm{~mm}^{2}$, with the flexible forceps $7.1 \pm 9.3 \mathrm{~mm}^{2}$, and with the cryoprobe $14.4 \pm 12.8 \mathrm{~mm}^{2}$ (Fig. 1). Rigid forceps biopsies were significantly larger than samples taken by cryoprobe $(p<0.001)$ and flexible forceps $(p<0.001)$. Biopsies by cryoprobe were significantly larger than flexible forceps biopsies, too $(p<0.01$; one-way ANOVA, with Bonferroni correction).

A deep biopsy containing fatty tissue was obtained in $63 \%$ of the rigid forceps biopsies, in $49.5 \%$ of the samples harvested with the cryoprobe and in $39.5 \%$ of the biopsies by flexible forceps (see Table 1 ).

In 66 out of all 80 cases (83\%) a deep biopsy was obtained by using the combination of all three described methods.

\section{Histopathologic diagnoses}

In the histopathological work-up, 43/80 malignant (54\%) and $37 / 80$ non-malignant (46\%) diagnoses were found (see Table 2).

In 79/80 cases (98.7\%, $95 \% \mathrm{CI}$ cannot be calculated) a diagnosis was obtained by rigid forceps biopsy. This was true in $73 / 80$ cases $(91.3 \%, 95 \%$ CI $86.0-96.5 \%)$ for cryoprobe samples and in 74/80 cases $(92.5 \%, 95 \% \mathrm{CI}$ $88.6-97.4 \%)$ for biopsies taken by flexible forceps. According to the assumptions made for non-inferiority, the diagnostic yield achieved with cryobiopsies was inferior to the yield rigid forceps biopsies (Difference: $12.7 \%$ ), but non-inferior to the flexible method (Difference: $6.5 \%$ ). The diagnostic yield was also different between samples harvested with rigid or flexible forceps (Difference: $10.1 \%$ ), therefore non-inferiority could neither be established for this comparison.

Analyzed per patient, in 73/80 cases (91\%) all three forceps techniques showed the concordant histopathological result. In $3 / 80$ cases $(4 \%)$, only the samples gained by rigid forceps showed the diagnostic histology. In $1 / 80$ case $(1 \%)$ an idiopathic pleuritis turned out to be a malignant mesothelioma after 12 month follow-up which was not detected in the thoracoscopic samples during the study.

\section{Complications of the procedure}

No complications such as bleeding or pain occurred during the procedure in any of the biopsy techniques. Furthermore, after the procedure no complications such as empyema or prolonged fistula were noted.

\section{Discussion}

This prospective study compared the two established biopsy techniques (rigid and flexible forceps biopsy) with the use of cryotechnique during medical thoracoscopy. 


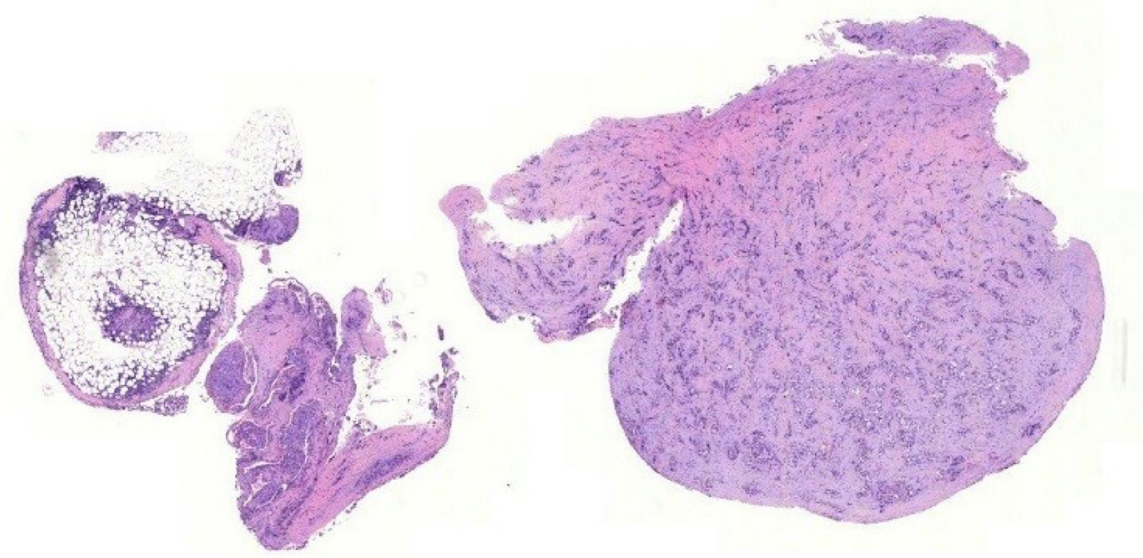

Fig. 2 Histological comparison of biopsy techniques: diagnosis of pleural manifestation of a pulmonary, TTF1-positive adenocarcinoma

In comparison, cryobiopsies showed a significantly larger biopsy size and depth than flexible forceps biopsies. On the other hand, rigid forceps biopsies showed, as expected, the significantly largest size and depth and the highest diagnostical yield. As cryotechnique can be used during semi-rigid thoracoscopy, and if a rigid forceps biopsy is not available, one could speculate that this inexpensive technique could overcome the problem of a too small size of flexible forceps. Furthermore, important for the pathologist was the fact that samples gained by cryotechnique showed less tissue damage in an overall very good quality (Figs 2, 3, 4 and 5) which was already described for lung biopsies [25, 26].

However, in the histopathological work-up, all three biopsy methods had a diagnostic yield of more than $90 \%$; in $91 \%$ of the cases the three different techniques showed the same histologic result. In one patient, after a 12-monthfollow-up that was carried out for all patients, a malignant mesothelioma was detected, that had not been found in any of the three techniques during medical thoracoscopy. This data demonstrates the non-inferiority concerning diagnostic (histological) accuracy of cryotechnique only in comparison to flexible forceps biopsy.

Furthermore, our study demonstrated the safety of the use of cryotechnique during medical thoracoscopy. No biopsy-related complications such as major bleeding or pain after tearing the probe were noted. These findings confirm the preliminary data by Rozman et al. [29], describing parietal pleural biopsies obtained by cryoprobe as safe.

In this series of 80 patients the histological diagnosis of malignant mesothelioma was only detected three times. Especially for this diagnosis the depth and quality of the biopsy is extremely important [31]. As a next step, a larger series including more patients suffering from malignant mesothelioma should be examined in a multicenter study, as this diagnosis is the
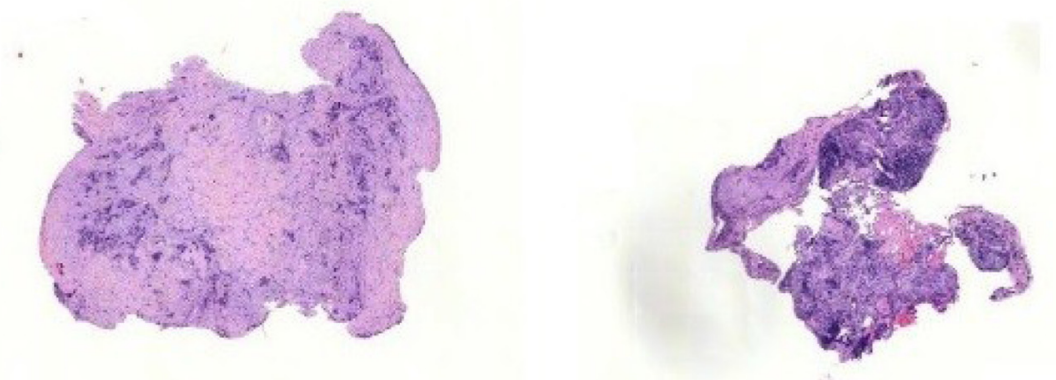

Fig. 3 Flexible forceps biopsy of a pleural carcinomatosis of pulmonal adenocarcinoma: pleural connective tissue and desmoplastic stroma (left side) with infiltrates of a non-small cell carcinoma (size $3,88 \mathrm{~mm}^{2}$ ) 

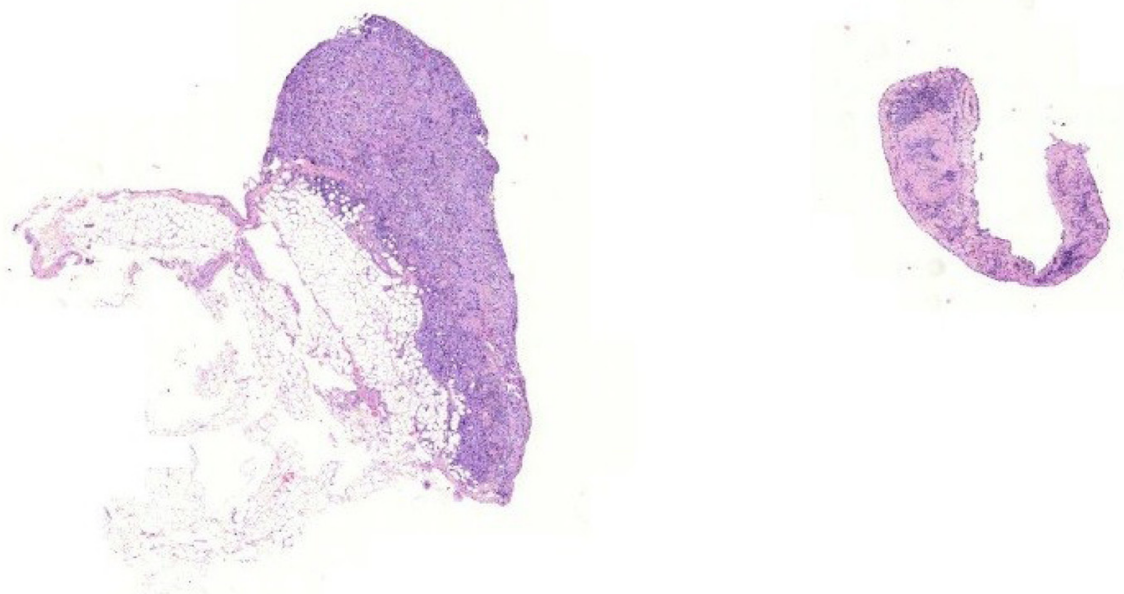

Fig. 4 Cryobiopsy of a pleural carcinomatosis of pulmonal adenocarcinoma: pleural fat tissue (left side) and pleural connective tissue (right side) with infiltrates of a non-small cell carcinoma (size $11,57 \mathrm{~mm}^{2}$ )

most frequently missed by medical as well as surgical thoracoscopy [32]. As a hypothesis, the higher number of deep biopsies containing fatty tissue should enable to detect mesothelioma with a higher yield of cryobiopsy compared to flexible forceps biopsy [31].

\section{Conclusion}

In summary, cryobiopsy obtained during medical thoracoscopy is a safe method with high diagnostic value, comparable to flexible forceps biopsy, but inferior to rigid forceps biopsies. Samples are smaller and less deep than rigid forceps biopsies, but significantly larger and deeper than samples gained by flexible forceps. Therefore, the use of cryobiopsy in semirigid thoracoscopy can not yet be generally recommended to replace rigid forceps biopsies during medical thoracoscopy.

The quantity of harvested tissue becomes increasingly important, because personalized therapy concepts especially for non-small cell lung cancer and breast cancer

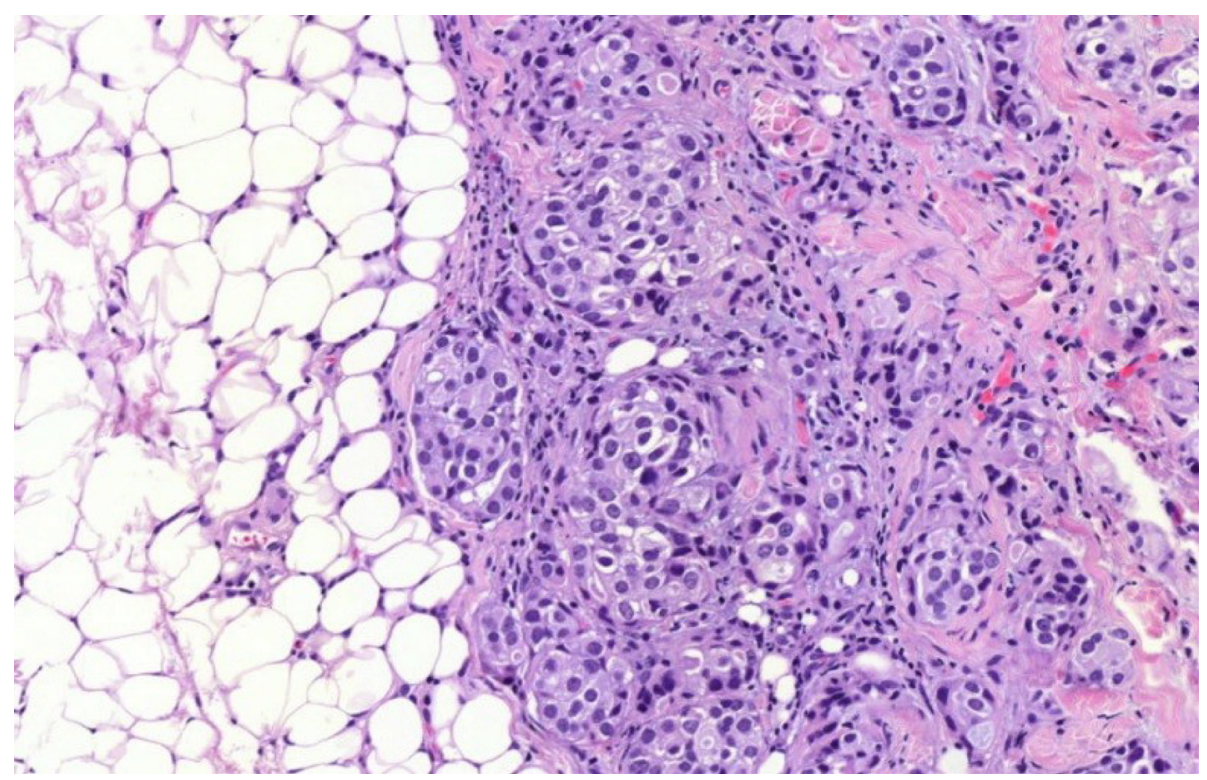

Fig. 5 Magnification of the cryobiopsy in Fig. 3: fat tissue (left side), which is infiltrated by tumor nests with glandular differentiation (right side), a manifestation of an adenocarcinoma respect 
demand more pathologic investigations. This will favour the use of cryotechnique where rigid forceps biopsies are not available or cannot be used.

\section{Abbreviations}

$\mathrm{Cl}$, confidence interval; $\mathrm{HE}$, hematoxylin-eosin; mm, millimeter; SD, standard difference

\section{Acknowledgements}

This work is a part of the doctoral thesis of author Sergej Griff, being performed at the Charité - University of Medicine in Berlin, Germany.

\section{Funding}

Does not apply to this particular manuscript.

\section{Availability of data and materials}

The datasets supporting the conclusions of this article are completely included within this article.

\section{Authors' contributions}

HW performed thoracoscopies and wrote the main part of the paper. NS corrected the paper. MB performed thoracoscopies. TB corrected the paper and worked out the statistical analysis. CD performed thoracoscopies. RS corrected the paper and took part in the histopathological and statistical analysis. TM performed histopathological analysis and corrected the paper. SG performed histopathological analysis and took part in writing and correcting the paper. All authors read and approved the final manuscript.

\section{Competing interests}

Henrik Wurps, Nicolas Schönfeld, Torsten T. Bauer, Mathias Bock, Christian Duve, Rica Sauer, Thomas Mairinger and Sergej Grif declare that they have no financial or non-financial competing interests.

\section{Consent for publication}

Does not apply to this particular manuscript.

\section{Ethics approval and consent to participate}

Prior to thoracoscopy and study enrollment, all patients were informed and written consent for participation and publication of the data was obtained. The study was approved by the medical ethics committee of the Charite Universitätsmedizin Berlin (Ethikkommission, Ethikausschuss 4 am Campus Charité - Mitte)

\section{Endnotes}

Does not apply to this particular manuscript.

\section{Author details}

'Department of Respiratory Medicine, Lungenklinik Heckeshorn, HELIOS Klinikum Emil von Behring, Berlin, Germany. ${ }^{2}$ Department of Pneumology and Institute of Pathology, HELIOS Klinikum Emil von Behring, Berlin, Germany.

Received: 6 April 2016 Accepted: 6 June 2016

Published online: 07 July 2016

\section{References}

1. Ernst $\mathrm{A}$, Hersh $\mathrm{CP}$, Herth $\mathrm{F}$, et al. A novel instrument for the evaluation of the pleural space: an experience in 34 patients. Chest. 2002;122:1530-4.

2. McLean AN, Bicknell SR, McAlpine LG, et al. Investigation of pleural effusion: an evaluation of the new Olympus LTF semiflexible thoracofiberscope and comparison with Abram's needle biopsy. Chest. 1998;114:150-3.

3. Munavvar M, Khan MA, Edwards J, et al. The autoclavable semirigid thoracoscope: the way forward in pleural disease? Eur Respir J. 2007:29:571-4.

4. Rozman A, Camlek L, Kern I, et al. Semirigid thoracoscopy: an effective method for diagnosing pleural malignancies. Radiol Oncol. 2014;48:67-71.

5. Lee P, Hsu A, Lo C, et al. Prospective evaluation of flex-rigid pleuroscopy for indeterminate pleural effusion: accuracy, safety and outcome. Respirology. 2007;12:881-6
6. Ishida A, Ishikawa F, Nakamura M, et al. Narrow band imaging applied to pleuroscopy for the assessment of vascular patterns of the pleura. Respiration. 2009;78:432-9.

7. Schönfeld N, Schwarz C, Kollmeier J, et al. Narrow band imaging (NBI) during medical thoracoscopy: first impressions. J Occup Med Toxicol. 2009:4:24.

8. Wang Z, Tong Z, Li H, et al. Semi-rigid thoracoscopy for undiagnosed exudative pleural effusions: a comparative study. Chin Med J. 2008;121:1384-9.

9. Lee P, Colt HG. Rigid and semirigid pleuroscopy: the future is bright. Respirology. 2005;10:418-25.

10. Rozman A, Camlek L, Marc-Malovrh M, et al. Rigid versus semi-rigid thoracoscopy for the diagnosis of pleural disease: A randomized pilot study. Respirology. 2013;18:704-10.

11. Nattusamy L, Madan K, Mohan A, Hadda V, Jain D, Madan NK, Arava S, Khilnani GC, Guleria R. Utility of semi-rigid thoracoscopy in undiagnosed exudative pleural effusion. Lung India. 2015;32:119-26.

12. Sheski FD, Mathur PN. Endoscopic treatment of early-stage lung cancer. Cancer Control. 2000;7:35-44.

13. Gorenstein A, Neel 3rd HB, Sanderson DR. Transbronchoscopic cryosurgery of respiratory structures: experimental and clinical studies. Ann Otol Rhinol Laryngol. 1976:85:670-8.

14. Herth FJ, Eberhardt R, Ernst A. The future of bronchoscopy in diagnosing, staging and treatment of lung cancer. Respiration. 2006;73:399-409.

15. Vergnon JM, Huber RM, Moghissi K. Place of cryotherapy, brachytherapy and photodynamic therapy in therapeutic bronchoscopy of lung cancers. Eur Respir J. 2006;28:200-18.

16. Hetzel M, Hetzel J, Schumann C, et al. Cryorecanalization - a new approach for the immediate management of acute airway obstruction. J Thorac Cardiovasc Surg. 2004;127:1427-31.

17. Deygas N, Froudarakis M, Ozenne G, et al. Cryotherapy in early superficial bronchogenic carcinoma. Chest. 2001;120:26-31.

18. Asimakopoulos G, Beeson J, Evans J, et al. Cryosurgery for malignant endobronchial tumors: analysis of outcome. Chest. 2005;127:2007-14.

19. Mathur PM, Wolf KM, Busk MF, et al. Fiberoptic bronchoscopic cryotherapy in the management of tracheobronchial obstruction. Chest. 1996:110:718-23.

20. Hetzel J, Eberhardt R, Herth FJ, et al. Cryobiopsy increases the diagnostic yield of endobronchial biopsy: a multicentre trial. Eur Respir J. 2012;39:685-90

21. Franke KJ, Theegarten D, Hann von Weyhern C, Nilius G, Brueckner C, Hetzel J Hetzel M, Ruhle KH, Enderle MD, Szyrach MN Prospective controlled animal study on biopsy sampling with new flexible cryoprobes versus forceps: evaluation of biopsy size, histological quality and bleeding risk. Respiration. 2010;80(2):127-32

22. Schumann C, Hetzel J, Babiak AJ, Merk T, Wibmer T, Möller P, Lepper PM Hetzel M Cryoprobe biopsy increases the diagnostic yield in endobronchial tumor lesions. J Thorac Cardiovasc Surg. 2010;140(2):417-21.

23. Babiak A, Hetzel J, Krishna G, Fritz P, Moeller P, Balli T, Hetzel M. Transbronchial cryobiopsy: a new tool for lung biopsies. Respiration. 2009;78:2003-8. Aktas Z, Gunay E, Hoca NT, et al. Endobronchial cryobiopsy or forceps biopsy for lung cancer diagnosis. Ann Thorac Med. 2010; 5: 242-246.

24. Franke KJ, Szyrach M, Nilius G, et al. Experimental study on biopsy sampling using new flexible cryoprobes: influence of activation time, probe size, tissue consistency, and contact pressure of the probe on the size of the biopsy specimen. Lung. 2009;187:253-9.

25. Griff S, Ammenwerth W, Schönfeld N, et al. Morphometrical analysis of transbronchial cryobiopsies. Diagn Pathol. 2011;6:53.

26. Griff S, Schönfeld N, Ammenwerth W, Blum TG, Grah C, Bauer TT, Grüning W Mairinger T, Wurps H. Diagnostic yield of transbronchial cryobiopsy in nonneoplastic lung disease: a retrospective case series. BMC Pulm Med. 2014; $14: 171$

27. Bonniot J-PA, Homasson J-PD, Roden SL, et al. Pleural and lung cryobiopsies during thoracoscopy. Chest. 1989;95:492-3.

28. Sasada S, Kawahara K, Kusunoki Y, et al. A new electrocautery pleural biopsy technique using an insulated-tip diathermic knife during semirigid pleuroscopy. Surg Endosc. 2009;23:1901-7.

29. Rozman A, Camlek L, Marc-Malovrh M, Kern I, Schönfeld N. Feasibility and safety of parietal pleural cryobiopsy during semirigid thoracoscopy. Clin Respir J. 2014; doi:10.1111/crj.12256. 
30. Loddenkemper R, Schönfeld N. Medical thoracoscopy. Curr Opin Pulm Med. 1998:4(4):235-8

31. Husain AN, et al. Guidelines for pathologic diagnosis of malignant mesothelioma. Arch Pathol Lab Med. 2013;137(5):647-67.

32. Walters J, Maskell NA. Biopsy techniques for the diagnosis of mesothelioma. Malig Mesothelioma Springer. 2011;189:45-55.

Submit your next manuscript to BioMed Central and we will help you at every step:

- We accept pre-submission inquiries

- Our selector tool helps you to find the most relevant journal

- We provide round the clock customer support

- Convenient online submission

- Thorough peer review

- Inclusion in PubMed and all major indexing services

- Maximum visibility for your research

Submit your manuscript at www.biomedcentral.com/submit 